\title{
POSCONFLICTO Y REFORMA MILITAR: REFLEXIONES Y RCOMENDACIONES A PROPÓSITO DEL CASO COLOMBIANO TRAS LOS ACUERDOS DE LA HABANA
}

\section{Post-conflict and military reform: reflections and recommendtions on the Colombian case after the Havana agreements}

Alexander Arciniegas ${ }^{1}$

\section{La RSS: Elementos históricos conceptuales y normativos}

La post Guerra Fría y la globalización, impulsaron un cambio en la naturaleza de los conflictos armados, en el que se destaca la preeminencia de la guerra civil en el total de "violencia colectiva" a nivel global (TILLY, 2007). Como afirman (OROZCO\&TREJOS, 2014) y (TILLY, 2007), los actores de estos nuevo conflictos no eran ejércitos regulares sino guerrillas, milicias y grupos paramilitares que en contextos de estados débiles, ejercían la violencia por razones étnicas, religiosas o nacionalismo radicales.

Esta nueva tendencia se expresa en el hecho de que para la década de 2000 de un total de 33 conflictos armados a nivel global, tan solo dos conflictos no eran intraestatales: Eritrea-Etiopia e IndiaPaquistán, (OROZCO\&TREJOS, 2014). De este modo, al lado de la clásica misión de combate, las “operaciones de paz" pasaron a ocupar buena parte de la actividad de las FFAA occidentales, (TILLY, 2007); (CASTELLON, 2008).

En paralelo con esta nueva realidad de la seguridad internacional, la Comisión Palme de la ONU presentó en 1982 el concepto de "multidimensionalidad de las amenazas" que además del componente militar contemplaba elementos como bienestar económico, salud etc. (AGUILAR, 2014). Así, los estudios sobre seguridad comenzaron a considerar tanto el factor militar, como dimensiones de naturaleza socioeconómica y política; lo que se tradujo en el concepto de "seguridad humana", que aparece por primera vez en 1994, en el informe de la Comisión de Seguridad Humana del Programa de Nacional Unidas para el

\footnotetext{
1 Professor Universidad de Santander UDES-Bucaramanga. Doctor en Ciencia Política de la Universidade Federal do Rio Grande do Sul, (UFRGS) Porto Alegre/Brasil. Magister en Ciencia Política UFRGS; Abogado, Universidad Industrial de Santander UIS (2003). Realizó una estancia posdoctoral en el Programa de Pós-graduação em Ciência Política da UFRGS-Brasil (2014-2017). Fue profesor de la Facultad de Derecho y Ciencia Política de la UIS (2013). Profesor, investigador y analista en temas de política internacional, política comparada, seguridad y defensa. Áreas de interés: Seguridad Internacional, Defensa y estrategia; Relaciones ColombiaEstados Unidos; Política Comparada; Relaciones civiles-militares y Postconflicto. Email: arciniegascol@hotmail.com
} 
Desarrollo PNUD, (CASTELLON,2008). Este concepto ampliado de seguridad ${ }^{2}$ (AGUILAR, 2014), vino a decantarse con la producción teórica de la Escuela de Copenhague. De acuerdo con autores como Buzan, las presiones sistémicas impulsarían a los Estados a la interdependencia por lo que el aumento de la interacción internacional tornaría inapropiada la idea restringida de "seguridad nacional", (AGUILAR, 2014).

En consecuencia, una idea ampliada de seguridad que mantiene al Estado como principal unidad pero incorpora los componentes militar, político, económico, societal e ambiental, bajo la premisa de que estos son cruciales para la seguridad de las "colectividades humanas" (AGUILAR, 2014), es el fundamento de la denominada Reforma del Sector de Seguridad (RSS) o Security Sector Reform (SSR), (CASTELLON, 2008,p. 21).

Es por ello que hablar de RSS alude a una iniciativa integral o "multidimensional", que tiene como objetivos el control democrático y la promoción de los derechos humanos; el fortalecimiento de las capacidades estatales para garantizar seguridad, justicia y en última instancia, promover el desarrollo económico; así como contrarrestar la violencia estructural, (FOLKE BERNADOTTE ACADEMY, 2013). En este punto vale aclarar sin embargo que como anotan (BRUNEAU\&MATEI, 2008, p.8); (AGUILAR, 2014) existen múltiples definiciones de lo que sería RSS.

Finalmente, vale decir que aun cuando el impacto del 11-S debilitó aspectos importantes de la RSS como los orientados al desarrollo priorizando el combate al terrorismo (SEDRA, 2014); también contribuyó a decantar este modelo mostrando en la práctica, sus posibilidades y dilemas. Esto se dio por ejemplo, en casos como el de la reconstrucción de Afganistán. Primero con la operación Libertad Duradera llevada adelante por la coalición internacional encabezada por EUA. Y posteriormente, con la Fuerza Internacional de Asistencia a la Seguridad (ISAF), para garantizar la seguridad y el desarrollo, a través de programas de RSS: desmovilización, desarme y reintegración (DDR) de grupos armados ilegales, y reforma a las fuerzas militares y de policía, (CASTELLON, 2008).

Se considera aquí que más allá de su naturaleza polisémica, de las críticas de que puede ser objeto ${ }^{3}$, lo mismo que de sus alcances parciales en Irak, Afganistán, Sierra Leona, Liberia, el Congo o Guinea Bissau4, Kosovo y Timor Leste, la RSS puede servir de horizonte normativo y práctico para las reformas por las que debe pasar el aparato de seguridad militar y policial colombiano de cara al posconflicto con las FARC; pues dicho modelo se orienta a reedificar el aparato estatal, el sistema político democrático y a la reconciliación. Para en un segundo momento, avanzar en materia de infraestructura, salud, educación etc. Al tiempo que integra una visión amplia del sector de seguridad en la que civiles y militares trabajan juntos, (BRUNEAU \&

\footnotetext{
${ }^{2}$ Seguridad Humana incluye un componente referente a la eliminación de la violencia de la vida diaria o «freedom for fear» y un segundo componente, «freedom for wants», relativo a las necesidades básicas del individuo.

${ }^{3}$ Estos cuestionamientos pueden sintetizarse en los términos de (BLAIR, 2014) como el abismo entre principios y práctica. Cuestión que se refiere a problemas como ausencia de recursos suficientes para una reforma profunda y global del sector seguridad; límites para aplicar un abordaje democratizador en estados "neopatrimoniales", apropiación local insuficiente de parte de actores estatales y no estatales del país receptor del proceso, asistencia a las fuerzas de seguridad en las que prevalecen programas de entrenamiento y equipamiento en perjuicio de avances en términos de gobernanza y control democrático, (BLAIR,2014,p.100)

${ }^{4}$ Para un análisis sobre la RSS en este país ver (KOHL,2014).
} 
MATEI, 2008,p. 7) buscando la democratización, la prevención de conflictos y la reconstrucción en escenarios de postconflictos, (FOLKE BERNADOTTE ACADEMY, 2013).

En este orden, se entiende aquí por Sector Seguridad, al conjunto de instituciones, organismos o grupos-estatales o no estatales-que tiene como finalidad contribuir a preservar la seguridad o impartir justicia (CASTELLON, 2008). Este conjunto de actores se subdivide en 4 grupos como lo ilustra el siguiente cuadro,

Cuadro 1: Grupos del Sector Seguridad en RSS

\begin{tabular}{|l|l|}
\hline \multicolumn{2}{|c|}{ Grupos del Sector Seguridad en RSS } \\
\hline Núcleo del Sector de Seguridad: & $\begin{array}{l}\text { Fuerzas armadas, cuerpo de policía, gendarmería, servicios de } \\
\text { inteligencia, policía de aduanas, policías locales, efectivos de } \\
\text { protección civil, etc. }\end{array}$ \\
\hline Grupo de dirección y supervisión: & $\begin{array}{l}\text { El gobierno, el parlamento, ministerio de defensa, ministerio de } \\
\text { interior, ministerio de asuntos exteriores, ministerio de justicia, } \\
\text { ministerio de economía, etc. }\end{array}$ \\
\hline Grupo de justicia y estado de derecho & $\begin{array}{l}\text { Ministerio de justicia, sistema judicial, instituciones penitenciarias, } \\
\text { organismos relacionados con la defensa de los derechos humanos, } \\
\text { etc. }\end{array}$ \\
\hline Grupo de agentes no estatales & Guerrillas, milicias, compañías privadas de seguridad etc. \\
\hline
\end{tabular}

Fuente: Elaboración propia con base en (CASTELLON, 2008, p.28-29)

Así como no existe una definición acabada del proceso de RSS, en el que además puede participar un amplio conjunto de actores: instituciones internacionales ONU o OTAN, ONGs; instituciones académicas; consultoras privadas; instituciones estatales entre ellas las fuerzas armadas (AGUILAR, 2014,p.36), tampoco existe un modelo único de RSS pues este debe adaptarse a las singularidades de cada país, según se trate de alcanzar el desarrollo; consolidar una transición democrática o estabilizar el posconflicto, (CASTELLON, 2008). En consecuencia debe seguir principios como: la apropiación local del proceso; un sector de seguridad basado en la democracia, mayor control civil y prestación de cuentas; reforma de las estructuras y capacidades de las fuerzas de seguridad; presupuestos viables para apalancar las reformas; mayor articulación entre la política de seguridad y la política de desarrollo (CASTELLON, 2008); (BLAIR, 2014).

Ahora bien, como anota (AGUILAR, 2014, p. 29), la RSS como proceso holístico alude a un determinado contexto o "ambiente" como pueden ser los procesos de posconflicto en donde la seguridad se convierte en un presupuesto para el desarrollo económico y la democratización, (AGUILAR, 2014).

Fue justamente en el ámbito de la resolución de conflictos en donde los procesos de RSS fueron más discutidos y llevados a la práctica. Así, esta reforma fue implementada por la ONU y por distintas organizaciones regionales en las “operaciones de paz”. Paralelamente, entre 1992 y 2005 Naciones Unidas desarrolló cinco tipos de operaciones de paz: prevención del conflicto, promoción de la paz, mantenimiento de la paz, imposición de paz y construcción de paz. (AGUILAR, 2014). Siendo importante destacar para los 
fines de este artículo y en virtud de su caso empírico, las operaciones de manutención de la paz (peacekeeping) encaminadas a preservar la paz y apoyar la implementación de los acuerdos, (AGUILAR, 2014,p.26-27). Y las operaciones de construcción de paz (peace-building) que generalmente se implementan para complementar procesos de (peacekeeping) y están dirigidas a evitar que el conflicto se repita, lo mismo que a fortalecer las estructuras y las acciones indispensables para mantener la paz y viabilizar la reconciliación (AGUILAR, 2014). Tales medidas apuntan a restaurar las capacidades estatales para proveer seguridad y garantizar el orden público; apoyar la legitimidad de las instituciones políticas, la participación ciudadana, fortalecer el estado de derecho y promover el desarrollo socioeconómico (AGUILAR, 2014). Es así como en escenarios de posconflicto como el colombiano, la construcción de paz debe priorizar un amplio conjunto de actividades, que van desde desarmar ex combatientes, destruir armas y desarrollar tareas de desminado, hasta repatriar refugiado, proteger el medio ambiente, avanzar en la protección de los DDHH, reformar e fortalecer las instituciones gubernamentales, apoyar la reconciliación y proponer procesos de participación política, (RETTBERG, 2010, p.237).

Estas actividades centrales para la construcción de paz en Colombia enfrentan grandes desafíos pues como sostiene (AGUILAR,2014,p.29), el “ambiente” en el caso de estados atravesados por conflictos armados está determinado por la conjunción de problemas como: colapso del estado, instituciones políticas débiles o ausentes, débil control territorial por parte del estado, actores armados no estatales, violaciones a los derechos humanos, autonomía militar, sentimientos de desconfianza y venganza en la población, refugiados y desplazados, colapso de la economía y destrucción de la propiedad.

\section{Las FFAA colombianas en la década de 2000: fortalecimiento, expansión y asignaturas pendientes}

Durante la Guerra Fría y en virtud de la participación de los militares colombianos en la Guerra de Corea (1950-1953), los lineamientos estratégicos de las FFAA estuvieron marcados por la fuerte influencia estadounidense y por el anticomunismo, (OROZCO\&TREJOS, 2014).

De este modo, el peso de la Doctrina de la Seguridad Nacional conllevó a que la idea de "enemigo interno" tuviera una persistente vigencia, en un contexto de fuerte autonomía y de manejo castrense del orden publico interno resultado de la “doctrina Lleras” promulgada en 1958 a comienzos del Frente Nacional, (OROZCO\&TREJOS, 2014, p.221); (DAVILA,1998).

Con la caída de la "cortina de hierro”, el narcotráfico substituyó al comunismo como principal amenaza para la seguridad estadounidense. Mientras que en el plano interno, teniendo en cuenta que todos los actores del conflicto armado en mayor o menor medida, obtuvieron del negocio de la coca una importante fuente de rentas (CHERNICK, 2008), los límites entre contrainsurgencia y combate al narcotráfico fueron cada vez más difusos (OROZCO\&TREJOS, 2014).

El dramático escalamiento del conflicto interno desde mediados de los años noventa hasta bien entrada la década de 2000, impulsó durante la segunda mitad del gobierno Pastrana (1998-2002) un proceso de modernización militar especialmente en el Ejercito Nacional, que tuvo como ejes: la profesionalización 
de la tropa y el aumento de la movilidad operacional, (OROZCO\&TREJOS, 2014); (ARCINIEGAS, 2014); (SCHULTZE-KRAFT, 2012).

Uno de los hitos de esa reforma militar fue la Fuerza de Despliegue Rápido (FUDRA) creada en diciembre de 1999, en medio de las conversaciones de paz con las FARC que se extenderían hasta comienzos de 2002. Además de la decisión estratégica del estado colombiano para mejorar su poder disuasorio; la intervención de los EUA dentro del conflicto (ROJAS, 2015) que se concretó en los tres componentes del Plan Colombia: erradicación forzosa de cultivos ilícitos; reingeniería de las FFAA con la creación de batallones antinarcóticos; y en menor medida la política social (OROZCO\&TREJOS, 2014); determinaron el tipo de reforma militar que al final se concretó y sus objetivos estratégicos (ARCINIEGAS, 2014).

Posteriormente, el gobierno de Álvaro Uribe $(2002,2010)$ continuó la transformación del sector seguridad iniciada por su antecesor. Sin embargo, el liderazgo caudillista de Uribe y la Política de Defensa y Seguridad Democrática (PDSD), hicieron que las FFAA pasaron a la ofensiva en el plano estratégico alcanzando un protagonismo inusitado pues la seguridad en su dimensión coercitiva, se convirtió en la base de la gobernabilidad y de las políticas públicas, (OROZCO\&TREJOS, 2014).

Paralelamente y de acuerdo con (LEAL, 2015), el gasto en seguridad saltó de 2,8\% del PIB en 1994 a 5,2\% en 2009. Al tiempo que según (SCHULTZE-KRAFT, 2012), entre 2001 y 2007 el gasto en este sector alcanzó el 4,9\% del PIB, superando ampliamente el promedio latinoamericano que para ese mismo periodo fue del 1,6. Esta tendencia se mantuvo en la administración Santos, razón por la cual en 2012 y 2013, Colombia aparecía como el país de la región que destinaba más dinero del PIB en materia de defensa y seguridad, (LEAL, 2015).

En consonancia con su estrategia interna de mano dura, la política externa uribista se orientó a buscar apoyo internacional para erradicar lo que calificaba como una "amenaza terrorista". De esta manera, se alineó incondicionalmente con Washington en un momento en que la región había dado un giro hacia la izquierda, insertando el conflicto colombiano dentro de guerra al terror tras el 11 de septiembre y accediendo con ello a una importante fuente externa de apoyo político y militar (OROZCO\&TREJOS, 2014).

Al mismo tiempo, la PDSD aumentó el tamaño de las FFAA y profundizó su profesionalización; avanzó en la recuperación del control territorial reforzando la presencia permanente de la Policía Nacional en todos los municipios del país; creó nuevas Brigadas Móviles; Batallones de alta Montaña; programas de soldados campesinos; fortaleció el apoyo aéreo a través de aviones AC-47 o avión Fantasma, los helicópteros H-60 Arpía, UH-60 versión utilitaria, UH-1 N Huey II y MI-17; lo mismo que en términos de inteligencia humana y electrónica, OROZCO\&TREJOS, 2014).

Con base en la renovada capacidad militar del estado y con apoyo del Comando Sur (ARCINIEGAS, 2014), se puso en marcha el Plan Patriota (2004-2007), que complementó el componente antinarcóticos de la primera fase del Plan Colombia, iniciada dos años atrás, (OROZCO\&TREJOS, 2014); (ROJAS,2015). En el marco del Plan Patriota se ejecutó una campaña contrainsurgente de gran escala dirigida a golpear a las 
FARC en la que participaron unos 18.000 hombres de la Fuerza de Tarea Conjunta Omega (FUTCO), (ARCINIEGAS, 2014).

A pesar de sus enormes costos económicos y humanos el Plan Patriota desmanteló los ocho frentes que integraban el "dispositivo militar” de la FARC en el departamento de Cundinamarca para cercar Bogotá, al tiempo que debilitó su "retaguardia estratégica" en el sur oriente del país (OROZCO\&TREJOS, 2014, p.228), concretamente, el bloque Oriental la mayor y más poderosa estructura político militar de las FARC, (ARCINIEGAS, 2014).

Otras significativas acciones resultado del fortalecimiento del militar durante la década de 2000 y que llevaron a un desequilibrio estratégico en favor del Estado fueron las capturas de Simón Trinidad en 2004 y de Rodrigo Granda el "Canciller” de las FARC en 2005. A lo que se suma el bombardeo de territorio ecuatoriano en marzo de 2008 en el que fue abatido "Raúl Reyes". En esta operación por primera vez en la historia del conflicto armado, el estado consiguió golpear al Secretariado de las FARC, estado mayor de esa guerrilla. Posteriormente vendrían los golpes en contra de "Mono Jojoy” jefe del Bloque Oriental y “Alfonso Cano" comandante máximo de las FARC en 2010 y 2011 respectivamente.

A pesar del fortalecimiento coercitivo del estado en virtud del cual, Colombia tiene hoy la segundas fuerzas armadas más numerosa (425.000 efectivos) de Suramérica y uno de los dispositivos de movilidad aerotransportada y de reacción rápida más grandes de la región, (SCHULTZE-KRAFT, 2012). Y del consecuente debilitamiento de las FARC, la PDSD llevó a una excesiva militarización y "securitización" " de la agenda política doméstica (OROZCO\&TREJOS, 2014,p. 231) y externa deteriorando las relaciones con la región principalmente, con Ecuador y Venezuela.

Además, como advierte (SCHULTZE-KRAFT, 2012) pese al crecimiento y modernización de las FFAA y de los abundantes recursos domésticos y externos que se destinaron para ello, esta reforma militar se quedó corta en tres frentes claves: las relaciones de miembros de las FFAA con el paramilitarismo y el narcotráfico; la promoción y el respeto a los DDHH, y una reforma del sistema de justicia penal militar para que los actos cometidos fuera del servicio fueran juzgados por una justicia ordinaria eficiente.

Estos vacíos de la política de seguridad y defensa, se tradujeron en episodios como la utilización de la inteligencia del estado para perseguir opositores, periodistas y a la propia Corte Suprema de Justicia; las miles de ejecuciones extrajudiciales cometidas por miembros de la fuerza pública o "falsos positivos"”, a las que conllevaron tanto la política de incentivos económicos como la presión por resultados desde el Ejecutivo; lo mismo que la reciente expansión del fuero militar ${ }^{7}$. Tales abusos a los que se suman las resistencias dentro de la fuerza pública durante las negociaciones con las FARC (LEAL, 2015); arrojan

\footnotetext{
${ }^{5}$ Este concepto de acuerdo con (TICKNER, 2005) remite al uso político de la seguridad por parte de las elites que controlan el Estado. Esta dinámica que tiene en el discurso un componente central, es resultado de estructuras y procesos histórico políticos y sociales y en ultimas apunta a identificar o problema como una amenaza “existencial” a la seguridad estatal o de su población sacándolo de los marcos políticos ordinarios y más democráticos, de modo que para neutralizarlo el Estado queda legitimado para utilizar fundamentalmente, la fuerza.

${ }^{6}$ Esta denominación alude al asesinato de civiles para hacerlos pasar como criminales e inflar las cifras capturas o dados de baja.

${ }^{7}$ Aprobada en último debate reforma al Fuero Penal Militar”. En El Espectador, junio 10 de 2015.
} 
sombras sobre el control civil democrático y sobre el papel que jugará el núcleo de sector seguridad de cara al posconflicto.

De allí la necesidad de pensar la transformación del sector seguridad de cara a la paz por fuera de la militarización excesiva y en los marcos normativos de la RSS.

\section{Seguridad en el umbral del posconflicto}

La polarización interna, el insuficiente apoyo ciudadano a la negociación y el recelo dentro de la fuerza pública incidieron en que el tema de las transformaciones en las instituciones de seguridad no se incluyera dentro de las negociaciones de paz, como si sucedió en Sudáfrica, Irlanda y El Salvador (LLORENTE, BULLA \& GOMEZ,2015).

De hecho, el papel de las FFAA colombianas en el proceso de paz de la Habana presenta dos momentos: El primero en el que predomina el "ruido de sables" arranca en 2010 y obedece a que el ex presidente Uribe férreo adversario del proceso consiguió manipular el temor existente dentro del sector defensa y más puntualmente en el Ejercito en relación con un downsizing o el re direccionamiento del gasto y un segundo momento, que empieza a decantarse a finales de 2014 caracterizado por una postura más proactiva que a su vez se concreta en la presencia de representantes de la Fuerza Pública en la Mesa de Negociaciones dentro de la subcomisión técnica que acordó las condiciones del cese al fuego bilateral y dejación de armas, en la que desde marzo de 2015 participaron cuatro oficiales activos, liderados por el general Javier Flórez, antiguo comandante de la Fuerza de Tarea Conjunta Omega ${ }^{8}$.

Por lo anterior es claro que en la actual coyuntura la Fuerza Pública constituye un aspecto central dentro de los cambios institucionales que son imprescindibles para una situación de cierre total o parcial del conflicto armado interno, (LEAL, 2015). En otras palabras, así como desde 2002 las instituciones armadas vinieron a ocupar un espacio central en la política y el estado para hacer la guerra, hoy su reconversión es fundamental para construir la paz.

De este manera, parece lógico pensar que tras la desaparición de las FARC como organización armada, debe tener lugar una reconversión de las FFMM, tal y como ocurrió en Irlanda, Centro América y los Balcanes (SCHULTZE-KRAFT, 2012). Sin embargo, avanzar en esta transformación en Colombia, no es tarea fácil, tomando en cuenta que durante la década de 2000, la fuerza pública adquirió un tamaño y una centralidad sin precedentes en la dinámica política y en el cuadro estatal (ISACSON, 2010). Lo que profundizó su "espíritu de cuerpo”, su actitud reactiva frente a la intervención civil en áreas que consideran exclusivas y su acendrada creencia en que son la “esencia misma del estado” (LEAL, 2015).

De hecho, en una conferencia sobre la reforma doctrinaria que a mediados de 2016 se convirtió en la Doctrina Damasco, proceso que contó con el apoyo de EUA y la OTAN, el comandante del Ejército afirmó:

\footnotetext{
${ }^{8}$ Creada en 2003 la FUTCO fue la primera organización de las FFMM en utilizar el concepto de doctrina conjunta y lideró la ofensiva en el sur del país en contra del Bloque Oriental y Bloque Sur, principales estructuras militares de las FARC. Ver: https://www.ejercito.mil.co/?idcategoria=388882.
} 
"los cambios en la doctrina los hacemos nosotros, que somos los que sabemos de estos temas". "Aquí no va a venir ningún civil ni ninguna organización a hacernos esos cambios. Queremos dar la garantía de que es una doctrina que está al servicio de los más altos intereses de la Nación”. ${ }^{9}$

No en vano y como señalan (LLORENTE, BULLA \& GOMEZ, 2015) el debate sobre la reforma del sector seguridad en el escenario del fin del conflicto parece hoy detenido o encapsulamiento en los cuarteles o en algunos escenarios especializados.

Por esto es fundamental discutir abiertamente la reorganización de la fuerza pública para que pueda responder eficazmente a las demandas de seguridad de la Colombia post FARC, propiciando la participación de civiles y militares, pues de modo similar a lo sucedido en Sudáfrica, Guatemala y el Salvador, varias formas de violencia pueden proliferar tras los acuerdo de paz, por cuenta de fenómenos de fuerte impacto rural: narcotráfico, estructuras guerrilleras supérstites, paramilitarismo y minería ilegal, amenazando al orden público y la convivencia ciudadana allí donde el Estado ha ejercido históricamente menos presencia y control, (VELASQUEZ, 2015); (DELGADO, 2015).

De todas estas amenazas el paramilitarismo, representa el mayor obstáculo tanto para la seguridad de los desmovilizados, así como para la implementación de los acuerdos en términos de erradicación de cultivos ilícitos y restitución de tierras. A este respecto y contrario a lo que ha venido defendiendo el gobierno, en el sentido de que serían "bandas criminales" carentes de una finalidad política, es importante enfatizar que se trata de agrupaciones que pese a sus diversas moralidades, intereses y particularidades regionales y locales, actúan desde lo local, a partir de una visión” contrainsurgente” y de sus vínculos con miembros de la Fuerza Pública y con elites regionales y nacionales, (CUERVO\&ARENAS, 2016).

Según (INDEPAZ) unas 14 organizaciones neo paramilitares entre las que se destacan (LOS USUGA, LOS RASTROJOS, AUTODEFENSAS GAITANITAS), estarían actuando en 142 municipios de un total 1101 y en 22 de los 32 departamentos del país ${ }^{10}$; siendo que sus regiones de influencia coinciden con los territorios en donde operaron las Autodefensas Unidas de Colombia (AUC) desmovilizadas durante el gobierno Uribe.

Es importante advertir que la complejidad, adaptabilidad y penetración del paramilitarismo como expresión de la criminalidad no está circunscrita a la Colombia rural y periférica, sino que se extiende a los principales centros urbanos en donde controla desde rentas públicas hasta mercados de la criminalidad (CUERVO\&ARENAS, 2016). Además del paramilitarismo la seguridad ciudadana en las ciudades colombianas también es amenazada por otros fenómenos criminales: delincuencia organizada, delincuencia común, delitos sexuales, delincuencia juvenil etc. (VELASQUEZ, 2015; 10).

Otro aspecto problemático para la seguridad en el posconflicto es la combinación entre fragilidad estatal y penetración del narcotráfico, presente con mas intensidad en departamentos como Nariño, Cauca, Putumayo o Caquetá que concentran el $73 \%$ de la producción cocalera ${ }^{11}$; lo que se agrava aún más debido a

\footnotetext{
${ }^{9}$ Así será la transformación del Ejercito para la paz”, en El Tiempo, 26 de septiembre de 2015.

${ }^{10}$ La magnitud del fenómeno paramilitar” en El Espectador, 21 de abril de 2016.

${ }^{11}$ UNGASS suaviza aterrizaje de acuerdo de drogas con las FARC” en la Silla Vacía, 19 de abril de 2016.
} 
la presencia de actores armados ilegales, lo mismo que a la ausencia de una economía legal suficientemente robusta para satisfacer las necesidades de sus habitantes.

De esta manera es posible sostener que el fin de las FARC y eventualmente del ELN como estructuras armadas no conducirá por si solo al fin de la violencia. Y lo que es más grave, el paramilitarismo, el contrabando, la minería ilegal y las drogas ilícitas podrían potenciarse aprovechando los vacíos de poder dejados por la desmovilización de las FARC y de otras guerrillas, convirtiéndose en factores altamente desestabilizador del posconflicto, esto si las instituciones estatales no son eficaces para copar estos territorios (LLORENTE, BULLA \& GOMEZ, 2015).

\section{Seguridad para la paz: alternativas de corto y largo plazo}

En este sentido y tomando como base los trabajos de (LLORENTE, BULLA \& GOMEZ, 2015) y (VELASQUEZ, 2015), se presentan algunas opciones de corto y mediano plazo que apuntan a reorganizar la fuerza pública aprovechando las capacidades militares y policiales alcanzadas en los últimos tres lustros en la contención de la insurgencia, el narcotráfico; lo mismo a sugerir la creación de nuevas instituciones para avanzar en un escenario de posconflicto en el mediano y largo plazo; atendiendo las necesidades de seguridad rural y de seguridad ciudadana. Tales recomendaciones para utilizar las categorías que componen el Sector Seguridad en RSS y a los cuales se hizo referencia en la primera parte de este trabajo, se refieren a las instituciones que integran el núcleo del sector seguridad y de otro lado, al componente de dirección y supervisión.

En materia de seguridad rural los esfuerzos ${ }^{12}$ policiales se han desarrollado a través de la Dirección de Carabineros y Seguridad Rural creada en los años noventa y de los Escuadrones Móviles de Carabineros (EMCAR) puestos en marcha en los años 2000 (LLORENTE, BULLA \& GOMEZ, 2015,p.7).

A su turno, la presencia militar en la ruralidad se ha enfocado en neutralizar las organizaciones guerrilleras, los neoparamilitares, desarrollar tareas antinarcóticos, combatir la extorsión y proteger “infraestructura minero-energética” (LLORENTE, BULLA \& GOMEZ, 2015:7). Sin embargo, estos esfuerzos no han sido suficientes para resolver el "doble déficit" de seguridad en el campo relacionado con el combate militar y policial al crimen organizado y con atender las demandas cotidianas de seguridad y convivencia (LLORENTE, BULLA \& GOMEZ, 2015).

De suerte que para mejorar la seguridad en el campo y de modo complementario a la institucionalidad existente, podrían explorarse dos opciones una de corto plazo dirigida a responder al escenario inmediato que impone al "estabilización"13" de la paz y otra de largo plazo. En el entendido que corresponde a la fuerza pública en cuanto garante de los “derechos ciudadanos”, apoyar la desmovilización,

\footnotetext{
${ }^{12}$ Estos esfuerzos se enfocaron en el combate a redes de narcotráfico, la incautación de drogas e insumos químicos, la destrucción de laboratorios, erradicación de cultivos ilícitos, y protección de infraestructura económica.

${ }^{13}$ Se refiere con esto a "la etapa de transición del conflicto a la paz, en la que se deben desplegar acciones inmediatas para garantizar la estabilidad en los territorios en el conflicto y crear confianza de sus pobladores hacia el estado" ver, (LLORENTE, BULLA \&GOMEZ, 2015:9).
} 
el desarme y la reintegración, así como la implementación local y nacional de los acuerdos de La Habana ${ }^{14}$, (LLORENTE, BULLA \& GOMEZ, 2015,p.9).

Así las cosas, una alternativa para la estabilización inmediata del posconflicto colombiano tiene que ver con la creación del Cuerpo Integrado para la Transición (CIT). Este cuerpo dependería de la Consejería para el Posconflicto y no sería una nueva fuerza sino que estaría constituido por policías, militares y por integrantes de otros organismo públicos; al tiempo que podría incorporar civiles desarmados concretamente, excombatientes de la insurgencia que trabajarían en la implementación de los acuerdos (LLORENTE, BULLA \& GOMEZ, 2015).

El CIT tendría una dirección colegiada compuesta por un civil y una junta de generales comandantes de cada unidad integrante del mismo (LLORENTE, BULLA \& GOMEZ, 2015), permitiendo una importante interacción civil-militar.

Un aspecto interesante de esta alternativa para la transformación del sector seguridad es que el CIT desarrollaría funciones comunitarias y de promoción de la participación ciudadana, pero también tendría capacidades disuasorias frente a cualquier actor ilegal en los territorios de precaria o inexistente presencia estatal. Así mismo, además de responder por la seguridad en los territorios estaría encargado de formular e implementar políticas de combate al crimen organizado en estas mismas zonas, contando para ello con capacidades de inteligencia y facultades de policía judicial (LLORENTE, BULLA \& GOMEZ, 2015).

En relación con su despliegue en el territorio operaria únicamente en las municipalidades priorizadas por el Estado, territorios en donde contaría con unidades fijas y móviles; las primeras asentadas en las veredas mientras las segundas actuarían en zonas alejas y poco pobladas (LLORENTE, BULLA \& GOMEZ, 2015, p.11). En este punto es importante aclarar que los equipos del CIT lejos de ser homogéneos se integrarían de forma "modular" (más o menos, unidades del ejército, infantería de marina, carabineros o policía judicial) dependiendo de las características geográficas y problemáticas de cada territorio (LLORENTE, BULLA \& GOMEZ, 2015).

Finalmente, esta opción de corto plazo garantiza una fuerza de seguridad encargada exclusivamente de los requerimiento inmediatos en las zonas de la periferia del país priorizadas en la implementación de los acuerdos; involucra a todas las fuerzas sin alterar su estructura y dependencia funcional al tiempo que integra un liderazgo civil coordinado con los mandos policiales y militares, (LLORENTE, BULLA \& GOMEZ, 2015). Además, podría evolucionar hasta consolidarse como una fuerza hibrida que asuma las tareas frente a las cuales policías y militares tienen capacidades “insuficientes” o "inapropiadas", (LLORENTE, BULLA \& GOMEZ, 2015:7-8); (VELASQUEZ, 2015), contribuyendo a clarificar la tradicional ambigüedad en los roles policiales y militares que caracterizan al caso colombiano producto del conflicto armado.

\footnotetext{
${ }^{14}$ Estos acuerdos suscritos entre la guerrilla de las FARC-EP y el Gobierno de Colombia en noviembre de 2016 se estructuran sobre cuatro pilares fundamentales: Reforma rural integral; ampliación de la participación política; cese al fuego y hostilidades y desarme definitivo; solución al problema de drogas mediante la sustitución concertada con las comunidades de campesinos cocaleros, lo mismo que a través de la prevención y tratamiento del consumo como problema de salud pública; componente de justicia que implementa de un sistema integral de verdad, justicia, reparación y no repetición que tiene como instituciones claves la Comisión de la Verdad y la Jurisdicción Especial de Paz (JEP).
} 
En síntesis, el CIT sería una herramienta para estabilizar la situación de seguridad, proteger a los ciudadanos, la infraestructura y las instituciones del estado en las zonas más vulnerables del país; donde se complementaría con el resto de la institucionalidad estatal en el camino de generar desarrollo social y económico (LLORENTE, BULLA \& GOMEZ, 2015).

En segundo lugar, una alternativa institucional de mediano y largo plazo para fortalecer la seguridad rural en el posacuerdo podría contemplar la creación de una Guardia Nacional Rural (GNR), como un organismo especializado e intermedio entre lo militar y lo policial (VELASQUEZ, 2015).

A este respecto y como anotan (RUIZ, 2015);(LLORENTE, BULLA \& GOMEZ, 2015) la idea de crear este cuerpo armado inspirado en la Gendarmería francesa, no es nueva en el país pues se remonta a los gobiernos de Núñez y Reyes en 1889 y 1904 respectivamente; siendo retomada a comienzos de los noventa y más recientemente por el Presidente Santos ${ }^{15}$.

Es conveniente aclarar que las gendarmerías fueron creadas en Europa en los siglos XVIII y XIX para ofrecer seguridad a las regiones apartadas en tiempos en que no existían las policías civiles, que solo vinieron a surgir en la primera mitad del siglo XIX en Inglaterra y Francia (RUIZ, 2015).

Diferente del CIT la (GNR) sería un nuevo organismo que se sumaría a las armas que conforman la fuerza pública: Ejército, Armada, Fuerza Aérea y Policía. Como tal estaría adscrita al Comando General de las Fuerzas Militares o al Ministerio de Defensa (VELASQUEZ, 2015). Territorialmente esta guardia tendría presencia nacional, una estructura centralizada con unidades “desconcentradas" para prestar seguridad en las zonas rurales; contaría con entrenamiento en doctrina y operaciones militares para facilitar operaciones conjuntas, al tiempo que dispondría de: aeronaves, blindados y armamento de infantería ligera, (LLORENTE, BULLA \& GOMEZ, 2015:14). Además, debería contar de una estructura de policía judicial y actuaría en coordinación con la Fiscalía (VELASQUEZ, 2015).

En términos de su composición, esta arma podría integrar desmovilizados previo paso por la justicia transicional, al tiempo que debería incorporar proporcionalmente personal y logística de las FFMM (VELASQUEZ, 2015).

La principal ventaja de una GNR es asumiría la seguridad en las regiones rurales de difícil acceso con el entrenamiento, la doctrina y los medios necesarios para ello y conduciría a que militares y policías se ocuparan con mayor eficiencia de la defensa nacional y la seguridad ciudadana respectivamente.

De otro lado, en materia de seguridad ciudadana una reforma al sector seguridad podría contemplar tres alternativas. Crear un Ministerio de la Seguridad; Crear un Ministerio de la Policía como ocurrió en Sudáfrica o trasladar la Policía Nacional que desde mediados del siglo XX depende del Ministerio de Defensa, poniéndola bajo la órbita del Ministerio del Interior (LLORENTE, BULLA \& GOMEZ, 2015, p.14), (LEAL,2017). Ahora bien, tomando en cuenta que la creación de un nuevo sector dentro del Estado, -sea un Ministerio de la Seguridad o de la Policía- exige un enorme apoyo político sea que se tramite con fundamento en las facultades extraordinarias concedidas al Ejecutivo o mediante una reforma

\footnotetext{
${ }^{15}$ ¿Para qué sirve la gendarmería que Santos propone para el posconflicto?” En El Tiempo, 28 de enero de 2015.
} 
constitucional vía Congreso. Al tiempo que demanda importantes recursos fiscales, cosa nada fácil en la actual coyuntura económica. Estas dos opciones se consideran poco realistas como lo evidencia el hecho de que el Presidente Santos tras proponer la creación de un Ministerio de la Seguridad Ciudadana durante sus dos campañas presidenciales terminó abandonando la idea una vez en el gobierno.

En consecuencia, se considera que la reforma más viable pero no por eso menos importante, debería buscar reubicar a la Policía Nacional en un Ministerio del Interior fortalecido. Esta posibilidad como afirma (LEAL, 2015); (LEAL, 2017) tiene al menos dos ventajas. Por una parte, avanzar en la "desmilitarización” de la policía y por otro lado, fortalecer al Ministerio del Interior mejorando la escasa articulación del Ejecutivo nacional con las orbitas regionales y municipales, en términos de “coordinación y planeación” (LLORENTE, BULLA \& GOMEZ, 2015, p.19). Adicionalmente, permite contrarrestar la manera como en varias regiones del país los poderes locales, alcaldes, gobernadores, han sido cooptados o se han aliado con la criminalidad (LEAL, 2015).

La reubicación de la Policía Nacional no afectaría la actual división temática sectorial pero exigiría ecualizar la importancia de algunas direcciones dentro de la institución es el caso de la Dirección de Seguridad Ciudadana que ganaría un status mayor al ser la principal interlocutora con el Ministerio del Interior (LLORENTE, BULLA \& GOMEZ, 2017).

Con la reforma propuesta aquí el Ministerio del Interior en cuanto responsable de la seguridad ciudadana dispondría de una entidad operativa armada de alcance en todo el territorio, que estaría articulada en los planos estratégicos, táctico y operacional (LLORENTE, BULLA \& GOMEZ, 2015). Además y desde el punto de vista administrativo, podría tener una “dependencia funcional y orgánica parcial” a efectos de no alterar las "economías de escala en el sector defensa" o los componentes que la Policía coordinada con el Ministerio de Defensa, es el caso de los recursos para vivienda o retiro del personal (LLORENTE, BULLA \& GOMEZ, 2015,p.19).

De esta manera el traslado de la Policía Nacional al Ministerio de la política encargada de la seguridad ciudadana de la descentralización e interlocución con los otros niveles del gobierno mejorará la coordinación y planeación entre autoridades locales y “comandantes” de las unidades “desconcentradas” de la Policía (LLORENTE, BULLA \& GOMEZ, 2015, p.19).

\section{Considerações Finais}

En el presente artículo se partió de los elementos normativos del modelo de la RSS que se sintetizan en un abordaje integral para reformar el sector seguridad en el marco de la democracia, los derechos humanos, el fortalecimiento del estado y la búsqueda del desarrollo para pensar la cuestión de la restructuración de las FFAA colombianas que se impone como consecuencia de la paz con las FARC.

En ese sentido, luego de demostrar que pese a la modernización y profesionalización de la fuerza pública de los últimos años enfatizando contrainsurgencia y el combate al narcoterrorismo, permanecen serias deficiencias en términos de control civil democrático y derechos humanos. De modo que Colombia 
tendría una fuerza pública inadecuada para los tiempos de paz en donde además de contribuir a la implementación de lo acordado deberá enfrentar eficazmente expresiones criminales como narcotráfico, paramilitarismo, contrabando y minería ilegal, lo mismo que los desafíos de la delincuencia común en los territorios rurales y en los espacios urbanos. Se formularon algunas ideas de corto, medio y largo plazo para una transformación del núcleo del sector seguridad y de sus órganos de supervisión y dirección adecuándolos al nuevo escenario estratégico que se abre para el Estado colombiano con la firma de los acuerdos de La Habana, sugerencias que aunque lejos de ser una propuesta acaba de reformas son un paso inicial para avanzar en la estabilización del posconflicto y en la construcción de una paz duradera.

\section{REFERÊNCIAS}

ARCINIEGAS, Alexander (2014). Relações Civis-Militares na América do Sul: O caso colombiano durante o Plano Colômbia (2000-2010). Tese de Doutorado em Ciência Politica- UFRGS, Porto Alegre, 2010, (263) p.

AGUILAR, Sergio. Reforma do Setor de Segurança: visão geral e proposta de planejamento. Em AGUILAR, Sergio (Orgs) Reforma do Setor de Segurança, teoria, prática e critica. Cap. 1, p. 9-91, São Paulo: Editora Porto de Ideias, 2014.

BLAIR, Stephanie. Uma critica à Reforma do Setor da Segurança. Em AGUILAR, Sergio (Orgs) Reforma do Setor de Segurança, teoria, prática e critica. Cap. 2, p. 92-129, São Paulo: Editora Porto de Ideias, 2014.

BRUNEAU, Thomas; MATEI, Cristiana. Towards a new conceptualization of democratization and civilmilitary relations. Disponible en: [https://fsi.stanford.edu/sites/default/files/evnts/media/Bruneau_final_file.pdf]. Acceso en 05/09/2017.

CASTELLON, Joaquín. Qué entendemos por Reforma del Sector Seguridad. En la reforma del Sector de Seguridad: El nexo entre la seguridad, el desarrollo y el buen gobierno. Cuadernos de Estrategia, Instituto Español de Estudios Estratégicos, Ministerio de Defensa 138, p. 16-31, 2008. Disponible en: $\quad$ http://www.ieee.es/Galerias/fichero/cuadernos/CE_138_Reforma_Sector_Seguridad.pdf>. Acceso en 05/09/2017.

CUERVO Henry; ARENAS Julio (2016). Presidente Santos es urgente el desmonte del paramilitarismo. Disponible en: [https://www.arcoiris.com.co/2016/04/presidente-santos-es-urgente-el-desmontedel-paramilitarismo/]. Acceso el 05/06/2017).

DAVILA, Andrés. El juego del poder: historia, armas y votos. Bogotá: UNIANDES, CEREC, 1998.

DELGADO, Jairo. 2016-2018: perspectiva de reformas al modelo de seguridad en Colombia. Opeal Observatorio de Política \& Estrategia en américa latina. Disponible en: [http://opeal.net/index.php?option=com_k2 \&view=item \&id=22650:2016-2018-perspectiva-dereformas-al-modelo-de-seguridad-en-colombia \&Itemid=149]. Acceso el 05/06/2016).

INDEPAZ. Informe presencia de grupos narcoparamilitares en los primeros tres meses de 2016. Disponible en [http://www.indepaz.org.co/wp-content/uploads/2016/04/Presencianarcoparamilitar-2016.pdf]. Acceso el 28/06/17.

ISACSON, Adam. Enmendando el "Pacto". El Cambio en el Equilibrio Civil-Militar en la Colombia de Álvaro Uribe. En influencias y resistencias, militares y poder en América Latina. Santiago de Chile: FLACSO-Chile, Editorial Catalonia, 2009 
KOHL, Christoph. Os Desafios da Reforma do Setor de Segurança na Republica da Guiné-Bissau. Em AGUILAR, Sergio (Orgs) Reforma do Setor de Segurança, teoria, prática e critica. São Paulo: Editora Porto de Ideias, 2014.

LEAL, Francisco. Las Fuerzas Armadas en el Posconflicto. Disponible en: [https://www.razonpublica.com/index.php/conflicto-drogas-y-paz-temas-30/8525-las-fuerzasarmadas-en-el-posconflicto.html]. Acceso 19/11/2017.

Expectativas en el posacuerdo. Disponible en: [https://colombia2020.elespectador.com/politica/expectativas-en-el-posacuerdo]. Acceso 19/11/2017.

Posconflicto $\quad$ y $\quad$ Fuerza Pública. Disponible: [http://www.elespectador.com/noticias/politica/posconflicto-y-fuerza-publica-articulo-539314]. Acceso 20/02/2017.

LLORENTE, María. De la seguridad para la guerra a la seguridad para la paz. Para un debate de las opciones institucionales. Fundación Ideas para la Paz, Bogotá. Disponible:[http://cdn.ideaspaz.org/media/website/document/57210e6f84515.pdf]. $\quad$ Acceso 05/01/2017.

OROZCO, Gabriel: TREJOS. Fuerzas Armadas en Colombia: evolución, reforma y perspectivas en el contexto de la Globalización. Em AGUILAR, Sergio (Orgs) Reforma do Setor de Segurança, teoria, prática e critica. Cap. 5, p. 199-239, São Paulo: Editora Porto de Ideias.

RETTBERG, Angélica. Diseñar el futuro una revisión de los dilemas de la construcción de paz para el posconflicto. En RETTBERG, Angélica (Compiladora) Conflicto armado: Seguridad y construcción de paz en Colombia. Cap. 11. p. 373-394 Bogotá: Uniandes, 2010.

ROJAS, Diana. El Plan Colombia La intervención de Estados Unidos en el conflicto armado colombiano. IEPRI Universidad Nacional, Bogotá: Penguin Random House Grupo Editorial, 2015.

RUIZ, Juan. Policía Rural: i...Y para qué una gendarmería?. Disponible en [https://razonpublica.com/index.php/politica-y-gobierno-temas-27/8220-polic\%C3\%ADa-rural\%C2\%BF\%E2\%80\%A6y-para-qu\%C3\%A9-una-gendarmer\%C3\%ADa.html]. Acceso el 05/01/2017.

SEDRA, Mark. Reforma do Setor de Segurança em Países Afetados por Conflitos: a necessidades de uma abordagem de segunda geração. Em AGUILAR, Sergio (Orgs) Reforma do Setor de Segurança, teoria, prática e critica. Cap. 3, p. 130-159, São Paulo: Editora Porto de Ideáis, 2014.

SCHULTZE-KRAFT, Markus. La cuestión militar en Colombia: la fuerza pública y los retos de la construcción de la paz. Disponible en: [https://opendocs.ids.ac.uk/opendocs/bitstream/handle/123456789/2362/LaCuestionMilitar.pdf?se quence $=4 \&$ isAllowed=y]. Acceso el 05/01/2017.

TICKNER, Arlene. La securitización de la crisis colombiana, bases conceptuales y tendencias generales. En Revista Colombia Internacional Uniandes, número 60, p. 13-35, 2004. Disponible en: [https://revistas.uniandes.edu.co/doi/pdf/10.7440/colombiaint60.2004.01]. Acceso el 05/01/2017.

TILLY, Charles. Democracia. RJ, Editora VOZES, 2013.

VELÁSQUEZ, Carlos. La fuerza pública que requiere el postconflicto, Working Papers. 13. Fundación Ideas para la Paz. Bogotá. [http://cdn.ideaspaz.org/media/website/document/5547dc7eef110.pdf]. Acceso el 05/01/2017. 
Recebido em 21 de novembro de 2017. Aprovado em 2 de abril de 2018. 


\title{
RESUMO
}

Este artículo propone algunas sugerencias puntuales en relación con la reforma de la fuerza pública en Colombia de cara al posconflicto. Para ello parte del concepto de Reforma del Sector Seguridad y de su horizonte normativo. Posteriormente, se revisan los aspectos esenciales de la reforma militar emprendida en la década de 2000 tanto en sus fortalezas en el debilitamiento de las FARC como en sus deficiencias en términos de control civil democrático y de respeto de los DDHH. Finalmente, en el camino de superar tales deficiencias y de atender a las necesidades de seguridad del nuevo escenario estratégico resultado de los acuerdos de La Habana, se proponen algunas recomendaciones en el corto y largo plazo para avanzar en un posconflicto más estable y construir una paz duradera.

Palavras-chave: Reforma del Sector Seguridad, FFAA, Posconflicto.

\begin{abstract}
This article proposes some specific suggestions in relation to the reform of the public force in Colombia in the face of post-conflict. It starts with the concept of Security Sector Reform and its normative horizon. Subsequently, it reviews the essential aspects of the military reform undertaken in the 2000s, both in its strengths in weakening the FARC and in its deficiencies in terms of democratic civilian control and respect for human rights. Finally, in order to overcome such shortcomings and to meet the security needs of the new strategic scenario resulting from the Havana agreement, some recommendations are proposed in the short and long term to advance a more stable post-conflict and build a durable peace.
\end{abstract}

Key-words: Security Sector Reform, Armed Forces, Post-conflict. 